\title{
Real Time Monitoring of Water by use of Internet of Things
}

\author{
Rutwik Choughule $^{1}$, Shubham Jangam ${ }^{1}$, Chinmay Chiplunkar ${ }^{1}$, Omkar Kulkarni ${ }^{1}$, Bharat Mazire ${ }^{1}$, \\ Pranav Karkar ${ }^{1}$, Shriya Jadhav ${ }^{2}$ \\ Computer Engineer, Department of Computer, Marathwada Mitra Mandal's College of Engineering, Pune, India ${ }^{1}$ \\ Assistant Professor, Department of Computer, Marathwada Mitra Mandal's College of Engineering, Pune, India ${ }^{2}$
}

\begin{abstract}
In recent years, because of the faster advancement in the computer technology like IOT, it's easy to prepare a smarter, reliable and cost effective model in developing countries to handle one of basic need 'water'. The basic idea of the project is to determine the quality of water by measuring the contamination with the help of sensors, then transferring the sensed data to cloud where decision making is done and the final results will be intimated on the mobile device. IoT proves to be beneficial by providing real-time monitoring. The technology uses MQTT protocol for sending data from Arduino board to any distantly located server, broker application or cloud and receives data from same to any mobile application or web application.
\end{abstract}

Keywords: Internet of Things, Water management, Potential of Hydrogen.

\section{INTRODUCTION}

WATER is subject to the wide variety of contamination today's world where, for every single human there is at during acquisition, processing, storage and distribution, least one smart-tech device associated, a new concept is any of which could result in a degradation of water shaping its way through, forging a vast Community of quality. For applications in which water is ultimately these Devices. This Forgery in simpler terms is known as going to play vital role for human beings or biodiversity, Internet of Things or simply IOT. It is a need of any smart water management could be better solution in MODERN system to include procedures that generate and ensuring purity of water in any facets of life which also broadcast the outcome swiftly and consistently, if that leads to subjective evaluation of term 'water'. However, system wants to compete in today's World. Where the subjective evaluation is normally very complex, time- traditional approach of especially, Result Broadcasting, consuming and tedious work

Wireless sensing technology has advanced such a point, that the deployment of networks of low-cost devices for real-time monitoring is now possible. For this purpose, Arduino board, basic sensors (like $\mathrm{pH}$, salinity and turbidity sensor), Arduino compatible Wi-Fi shield, any cloud technology can be used. By using the board and sensors it is possible to sense the parameters of water and transmit them on cloud.

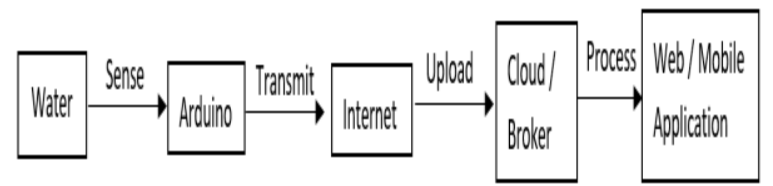

Fig. 1 Block diagram fails to meet this need, IOT is a preferred method that acts as a remedy to this issue. The Ease and Efficiency with which IOT helps achieving Inter-Device 'Communication and Control' is un-paralysed. For these very specific reasons IOT is included in this Project.

IOT is simply a community of Devices. Every mobile or desktop device that the implementer is using becomes an integrated part of this Project when he begins its execution. The Result-set generated by the services over the Cloud of the data received constantly from the 24-hour On-line Embedded Sub-System (Arduino Sub-system), can be published at any time instance to these desktop/mobile devices when needed. Hence with the help of IOT, this Project orients itself for the Community.

\section{IOT AND WATER MONITORING}

The result generated at cloud level will be shared to all mobile and web applications. The technology could have its use for different application, not only for local authorities but also for individual societies. With proper integration, this system can be used to monitor dams. Thissystem can also keep a real time watch on industries, what they actually releasing in water bodies through their waste water, sitting far away from exact location. In

Traditionally, a sample of water is taken from various distinct locations and then tested inlaboratories. After testing, the result sheet is generated and analysed to determine the quality of water. This process is time consuming and also can't keep a real time watch on water. Water quality monitoring is essential to control physical, chemical and biological characteristics of water. For example, drinking water should not contain any chemical 
materials that could be harmful to health; water for chemicals and contamination in water. US Environmental agricultural irrigation should have low sodium content; Protection Agency has carried out an extensive water for industrial uses should be low in certain inorganic experimental evaluation of water quality sensors to assess chemicals. In addition, water quality monitoring can help their performance on several contaminations. with water pollution detection and discharge of toxic

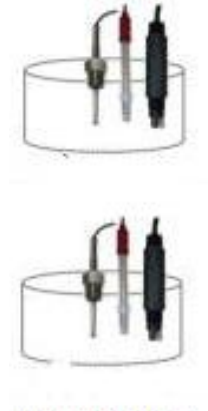

Water Sensor

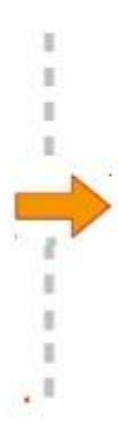

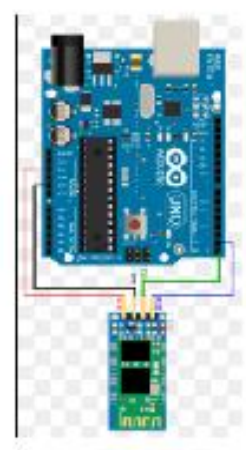

Ardunio

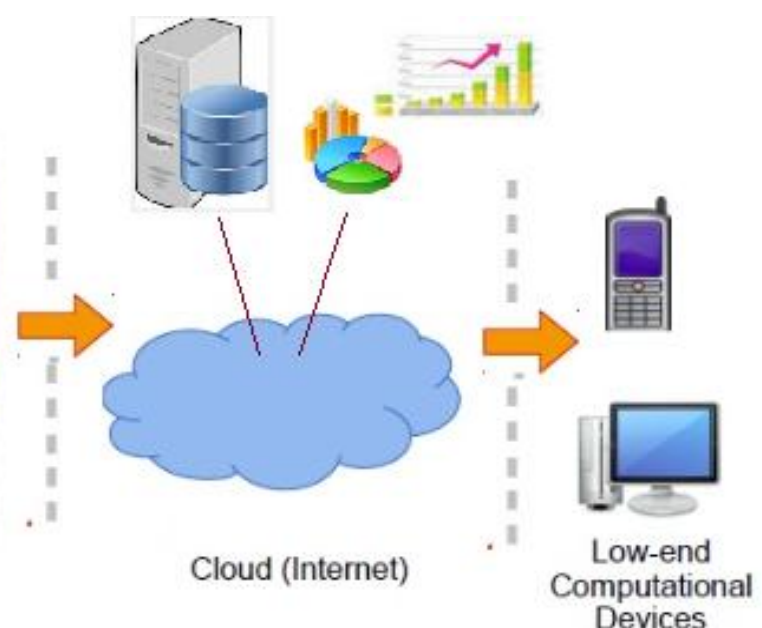

Devices

The main conclusion was that many of the chemical and Cloud: Data received from arduino is then converted into biological contaminants used have an effect on many the human understandable values. This data is then water parameters monitored including Turbidity, water processed over the cloud by using cloud APIs. These level, salinity and $\mathrm{pH}$. Thus, it is feasible to monitor and generated values are then stored into the database of cloud. infer the water quality by detecting changes in such Further this data is processed to generate results, which are parameters. In this project a System is been designed and accessible through mobile or web applications.

developed which allows the implementer to monitor the quality of water at consumer site. Sensors such $\mathrm{pH}$ (Potential of Hydrogen) sensor and Ultrasonic Sensor are used to get the water parameters and by using this parameters the proposed system decides whether the water is potable or not. The system takes the sensor values and stores it in the database. Later these stored values can be accessed through a mobile/web application, which shows the $\mathrm{pH}$ values and Level Percentile of the water, ultimately notifying the implementer whether it is safe to drink or not.

So an advanced approach is been introduced to keep a real time watch on water quality. The method uses Internet of Things (IoT), a network of devices, which enables these device to collect and exchange data. Usually, multiple things talking directly to each other in a given network are referred to as Clusters of the IoT.

Water sensors: This layer contains $\mathrm{pH}$ sensor, turbidity sensor, ultrasonic sensor. Sensors will sense the values continuously. This sensors are controlled by the Arduino board.

Arduino : This layer contains arduino board with WiFi shield. After fetching those values from sensors, the board will send that raw data (i.e. voltage levels, time difference etc.) immediately to the cloud using WiFi shield. The data is raw as it is still not mapped to its equivalent and Devices: This devices fetch the generated results from the cloud and display them over their respective applications. Also these applications will notify if the values are out of the standard value range.
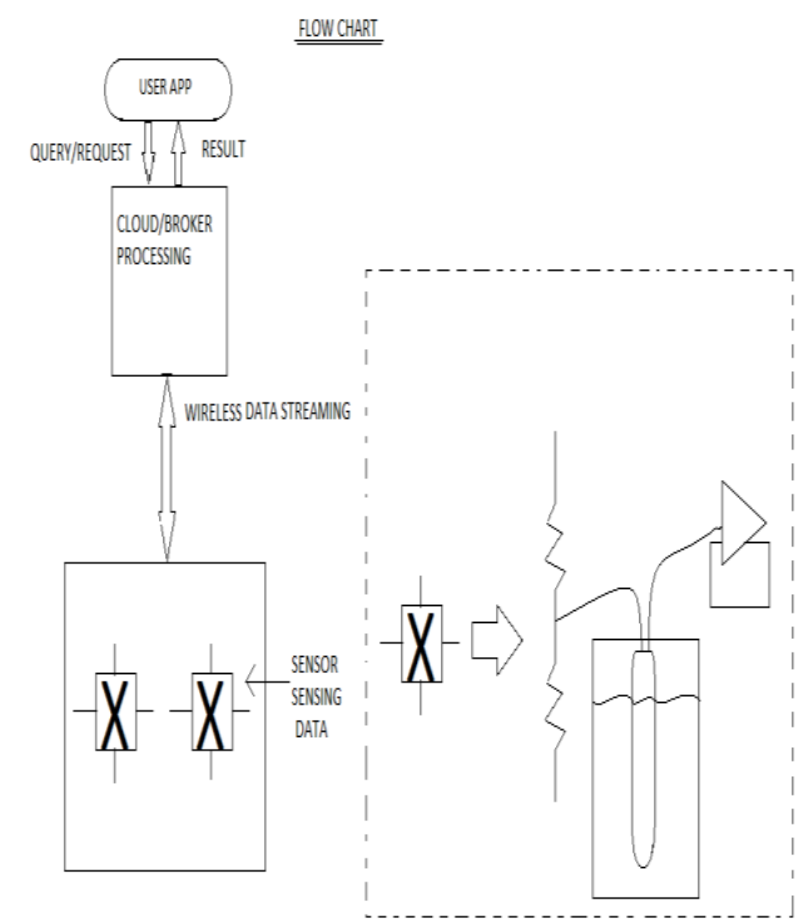
understandable values. 


\section{IOT PARADIGMS}

IoT is based on three paradigms - internet-oriented (middleware), things oriented (sensors) and knowledgeoriented (semantics)Internet-oriented: The cloud service provides coordination and management to the proposed system. The sensed data is stored and analyzed and the resultant information or result is delivered as a notification to the desired user on their mobile device or web portal. Cloud infrastructure provides efficient storage mechanism and accurate analysis thus providing flexibility, elasticity and reliability to the system.

Thing-oriented: Smart Objects can be defined as an objects which are able to describe its own possible interactions. Smart Object may provide the information about object properties, behavior and also, interaction information. In the proposed system different sensors can be used to test and check the purity of water. Here the sensors act like smart object.

Following are the different sensors:

\section{Turbidity Sensor:}

Turbidity is used to measure clarity of fluid. Turbidity is cloudiness of fluid caused due to presence of large number of particles in fluid which are not visible to naked eyes. An infrared ray is passed into fluid and the amount of scatter-ness is measured caused due to particles present in fluid. The infrared ray is transmitted and reflected back by suspended particles and the reflected light is received by sensors.

The higher the intensity of scattered light, the higher the turbidity. Turbidity level of water measuring between $0-5$ can be considered as safe for use.

\section{2. $\mathrm{pH}$ sensor :}

$\mathrm{pH}$ sensor is used to determine the chemical solution in water i.e whether the water is acidic, basic or neutral. The value ranges from 0 to $14 \mathrm{pH}$. If value is below 7, the water is considered as acidic, if above 7, it is basic \& at 7 it is neutral. According to Indian Standards water having $\mathrm{pH}$ between 6.5 to 8.5 is safe to drink.

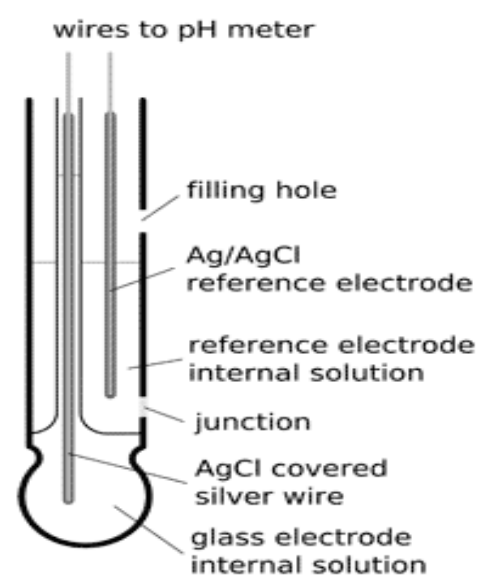

Fig. 4 pH electrode
3. Ultrasonic Sensor:

Ultrasonic sensor can be used to determine the level of water. It sends ultrasonic pulses from the sensor and is reflected back from surface to receiver. Time of transmitting and receiving of pulse is measured to calculate the distance between sensor and surface. The relationship between the distance up to the object $\mathrm{L}$ and the reflecting time $\mathrm{T}$ is expressed by the following formula:

$$
\mathrm{L}=\mathrm{C} * \mathrm{~T} / 2
$$

Where, $\mathrm{C}=$ velocity of sound.

$\mathrm{L}=$ measured distance.

$\mathrm{T}=$ Time of transmitting and receiving soundwave.

\section{Salinity Sensor :}

Salinity is the amount of salt dissolved in water.

It is measured in parts per thousand. High concentration of salt poses hazards for environment as well as affecting agriculture and infrastructure. Therefore by using sensors watch can be kept on concentration of salt in water and take necessary steps.

Range of salinity:

- Fresh water - Less than 1,000 ppm

- Slightly saline water - From 1,000 ppm to 3,000 ppm

- Moderately saline water - From 3,000 ppm to 10,000 ppm

- Highly saline water - From 10,000 ppm to 35,000 ppm

Knowledge-oriented: In this work a physical model is provided, for smart execution and quick review of water quality testing. Information to be monitored is autonomously provided based on sensor capabilities. This system is enriched with semantics to describe, share, and integrate information, inferring new knowledge related to water management and irrigation processes. It also helps to create machine-interpretable and self-descriptive data in the IoT domain. It enables interoperability between different data sources like sensors and other devices.

\section{IV.SYSTEM DESCRIPTION}

- Input: Sample Water

- Output: $\mathrm{pH}$, water level, salinity and turbidity levels.

- Success Conditions: Getting pH, water level, salinity and turbidity levels values on Android Device

- Failure Conditions: Failing in transmitting the water parameters to the Android device.

\section{Arduino Microcontroller:}

In this project an arduino uno microcontroller is used. This microcontroller will take the information from sensors. This gathered information then converted to digital form (using ADC present in microcontroller).

This arduino uno micro controller is based on ATmega328P. It has 14 digital input/output pins (of which 6 can be used as PWM outputs), 6 analog inputs, a $16 \mathrm{MHz}$ crystal oscillator. 
Vol. 6, Issue 3, March 2017

Specifications:

- Microcontroller

- Operating Voltage

ATmega328

- Input Voltage (recommended) 7-12V

- Input Voltage (limits)

- Digital I/O Pins PWM output)

- Analog Input Pins

- DC Current per I/O Pin

- DC Current for 3.3V Pin

- Flash Memory

- SRAM

- EEPROM

\section{WiFi Shield:}

CC3000 is wifi shield which is compatible with arduino board.

With the help of this shield data can be transmitted wirelessly.

This shield is mounted over arduino board \& helps in sending data to cloud or any storage system.

Specifications:

- Wireless Network Processor

- IEEE $802.11 \mathrm{~b} / \mathrm{g}$

- Embedded IPv4 TCP / IP stack

- Tx Power: $11 \mathrm{Mbps}$ is $+18 \mathrm{dBm}, \mathrm{CCK}$

- Rx sensitivity: $-86 \mathrm{dBm}, 8 \%$ packet error rate (PER), 11 Mbps

- Operating temperature range: $-20^{\circ} \mathrm{C}$ to $70^{\circ} \mathrm{C}$

\section{RESULT}

To get the sensors working, they are needed to be connected to the Arduino board and flash the proper sketch for smooth working. Let's take the Ultrasonic sensor first. This sensor is used to keep the track of water level. As the name suggests, this sensor works on the Ultrasonic sound and echo property. The sensor has echo and trigger pins which are used to calculate the water level. Also it will take power from Arduino board by $5 \mathrm{~V}$ pin. To start with, it is needed to provide a $10 \mathrm{~ms}$ or higher HIGH pulse to trigger pin. Then sensor will transmit the ultrasonic wave and it will sense its echo. As soon as echo arrives sensor output it through the pin echo i.e. echo pin goes HIGH. Then the duration between trigger and echo is measured, this is the twice the time required to cover that distance.

Distance will be given by equation,

$$
\begin{gathered}
\mathrm{cm}=(\text { duration/2) } / 29.1 \\
=\text { duration/58.2 } \\
\text { inch }=(\text { duration/2) } / 74 \\
=\text { duration/148 }
\end{gathered}
$$

Now, as the raw data is captured, it has to be transmitted to the cloud. IBM Bluemix, Thing Speak or any preferred cloud can be utilised. The APIs over the cloud will then plot the graph of the reading and provide the results and real-time values to its clients like android app or web apps.

\section{Ultrasonic sensor:}

\begin{tabular}{|l|l|l|}
\hline observations & $\begin{array}{l}\text { Ideal reading } \\
(\% \text { of water } \\
\text { level })\end{array}$ & $\begin{array}{l}\text { Sensor reading } \\
(\% \text { of water } \\
\text { level })\end{array}$ \\
\hline 1 & 25 & 24.14 \\
\hline 2 & 50 & 51.71 \\
\hline 3 & 80 & 79.12 \\
\hline
\end{tabular}

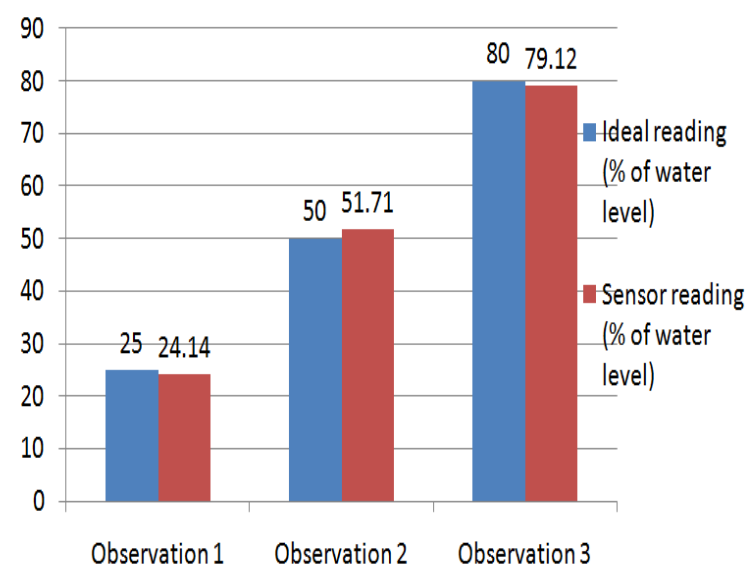

\section{REFERENCES}

[1] T.P. Lambrou, C.C. Anastasiou , C.G. Panayiotou, A Nephelometric Turbidity System for Monitoring Residential Drinking Water Quality, in Sensor Networks Applications, Experimentation and Logistics, 2009

[2] T.P. Lambrou, C.G. Panayiotou and C.C. Anastasiou, A Low-Cost Systemfor Real Time Monitoring and Assessment of Potable Water Quality atConsumer Sites, in IEEE Sensors 2012, 28-31 Oct 2012.

[3] S. Zhuiykov, Solid-state sensors monitoring parameters of water qualityfor the next generation of wireless sensor networks, Sensors and ActuatorsB: Chemical, Volume 161, Issue 1, pp 1-20, 2012

[4] A. Aisopou, I. Stoianov, N. Graham, In-pipe water quality monitoring inwater supply systems under steady and unsteady state flow conditions: Aquantitative assessment, Water Research, 46(1), pp. 235-246, 2012

[5] S. Panguluri, G. Meiners, J. Hall, J.G. Szabo, Distribution System WaterQuality Monitoring: Sensor Technology Evaluation Methodology andResults, U.S. Environmental Protection Agency, EPA/600/R-09/076, 2009

[6] J. Hall, A.D. Zaffiro, R.B. Marx, P.C. Kefauver, E.R. Krishnan, R.C.Haught, and J.G. Herrmann, On-line Water Quality Parameters as Indicators of Distribution System Contamination, Journal AWWA, 2007

[7] M.V. Storey, B. Gaag, B.P. Burns, Advances in on-line drinking waterquality monitoring and early warning systems, Water Research, Volume45, Issue 2, January 2011, Pages 741-747, ISSN 0043-1354 